\title{
Micro-RNA Biogenesis Genes (AGO1 and GEMIN4) Single Nucleotide Variants of Bad Prognosis and Poor Therapeutic Response in Egyptian Chronic Myeloid Leukemia Patients: Case-control Study
}

\author{
Wafaa Abd Elghany ${ }^{1}$ (i), Mohamed Emam², Usama Elnagar ${ }^{3}$, Rehab Helmy ${ }^{1}$, Osama H. Korayem ${ }^{4}$ Naglaa M. Hassan ${ }^{5}$ \\ ${ }^{1}$ Department of Clinical and Chemical Pathology, Faculty of Medicine, Cairo University, Cairo, Egypt; ${ }^{2}$ Department of Medical \\ Oncology, National Cancer Institute, Cairo University, Cairo, Egypt; ${ }^{3}$ Department of Medical Oncology, WadiEIneel Hospital, \\ Cairo, Egypt; ${ }^{4}$ Department of Biotechnology and Life Sciences, Faculty of Postgraduate Studies for Advanced Sciences, Beni- \\ Suef University, Beni-Suef, Egypt; ${ }^{5}$ Department of Clinical Pathology, National Cancer Institute, Cairo University, Cairo, Egypt
}

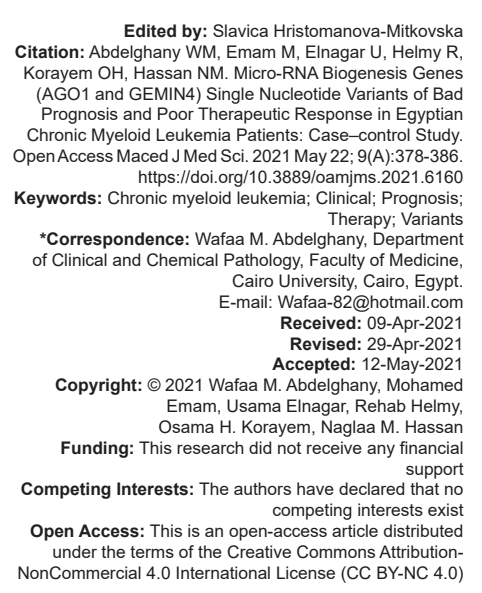

\begin{abstract}
BACKGROUND: Chronic myeloid leukemia (CML) is one of the most common hematological tumors. Gene candidate studies cleared the association of single genetic variants (SNVs) to the risk and progression in CML. MicroRNA biogenesis genes disruption contributes a fundamental role in carcinogenesis.

AIM: We aimed to determine the association between rs636832 and rs2740348 SNVs of AGO1 gene and GEMIN4 gene, respectively, and the risk and prognosis in CML Egyptian patients with 5 years survival estimation.

METHODS: The study was conducted on 110 newly diagnosed CML patients and 110 age and sex healthy matched controls. Real-time polymerase chain reaction utilizing TaqMan probes was operated to demonstrate genetic modalities of rs636832 and rs2740348.

RESULTS: No significance difference was observed between the cases and controls regarding the genotypic and allelic frequencies for both variants. On the other hand, the rs636832 GG genotype was more evident at a younger age of diagnosis and associated with the poor grades of the Sokal and Eutos scores. As well, rs2740348 CC genotype was encountered in high Eutos score levels. Regarding the response therapy, rs636832 GG genotype was overrepresented in the resistance to Imatinib while rs 2740348 CC genotype was prevalent in the resistance to both Imatinib and Nilotinib. Overall survival was of no statistical significance for both variants.
\end{abstract}

CONCLUSION: Our study revealed that the major homozygous genotypes of both variants were associated with bad prognostic clinical scores and poor response to therapy but with no role in CML risk.

\section{Introduction}

Chronic myeloid leukemia (CML) is BCR$A B L$ positive myeloproliferative disease affecting hematopoietic stem cell by clonal growth of leukemic progenitor cells with myeloid predominance [1]. It is considered one of the most hematological disorders, accounts $15 \%$ of all leukemia affecting the elderly with male predominance. The annual incidence of CML is $0.87 / 100,000$ subjects that increase 1.52 in age more than 70 [2]. The estimated deaths are 1.130 per year to be 1090 in 2018 [3]. CML comprises 15\% of leukemia as leukemia counted in Egypt in 2018 new cases 4314 with 3752 deaths [4].

Pathogenesis of $\mathrm{CML}$ depends on tyrosine kinase activity of the chimeric BCR-ABL (reciprocal translocation $t[9 ; 22][q 34 ; q 11])$ that acts the main target of therapy by tyrosine kinase inhibitors (TKI).
Multiple genetic variants showed increased evidence in pathogenesis as well clinical course and prognosis of CML [5]. MicroRNA (miRs) and its biogenesis genetic abnormalities found to be linked to hematological malignancies with little researches on CML [6].

MicroRNAs (miRs) are epigenetic modifiers of genetic expression by translational regulation and $m R N A$ processing. They are a single strand of small non-coding nucleotides (nt) ( 22 nt) that started its biogenesis as long primary (pri-miRNA) by RNA polymerase II (Pol II). Pri-miRNA is progressed to precursor miRNA (pre-miRNA) a 60-70-nt hairpin-shaped as action of RNase III enzyme Drosha and its cofactor in nucleus that extracted to cytoplasm by exportin 5 (Xpo5) to undergo second modification to 22 double-strand microRNA duplex by RNase III enzyme Dicer [7].

One strand of the miRNA duplexes combines into miRNA-induced silencing complex (miRISC) and 
converts to mature miRNA. The miRISC involves proteins as GEMIN3 and 4, and AGO1- 4 are encoded by miRNA biogenesis machinery genes. Their genetic abnormalities; deletion, insertion, mutations affect expression of several oncogenes and tumor suppressor genes with cancer risk, and progression susceptibility [8].

AGO1 gene is present on $1 \mathrm{p} 34.3$ chromosome, encodes one of the argonaute family proteins that have important actions in RNA interference (RNAi) and RNA silencing [9]. The rs636832 SNP is existed in the intron 8 of AGO1 gene, related to the risk of lung cancer and the lymphatic metastasis of gastric carcinoma [10], [11].

GEMIN 4 gene is subsisted on chromosome 17p13.3, encoding the Gemin4 protein which is essential component of the miRISC complex [12]. The rs2740348 single genetic variants (SNV) of GEMIN4 are found to be related to rise breast cancer risk and with reduced risk for prostate cancer development [9], [13].

AGO1 rs636832 interacts through Wnt pathway that has an important role in renewing of normal cells and its disruption is involved in carcinogenesis risk and behavior [11]. As well AGO1 was found to regulate the transcription activity through stimulation of phosphoinositide 3-kinase (PI3K/AKT) [14]. Wht pathway activation with subsequent PI3K/AKT signaling; is involved in CML progression and TKIs resistance [15]. Hence, AGO1 variants may participate in $\mathrm{CML}$ risk and prognosis.

PI3K/AKT and STAT5 pathways are essentially involved in the progression and TKI resistance in CML [16]. The N-terminal of STAT5a/b pathway proteins is the domain responsible for cytokine receptor binding, suppresses its autoactivation, and interacts with nuclear receptors as glucocorticoid receptors and mineralocorticoid receptor (MR) [16]. GEMIN4 has a regulator repressor function to MR receptor so its disruption can affect CML progression [17].

Galectin-1 (GAL1) is a beta galactoside binding protein that involved in tumor progression and metastasis. It acts as a bad prognostic marker in CML that enhance its transformation and treatment resistance. It has several pathways of action, including PI3K/AKT and binding to GEMIN4 that affects subsequently miRs biogenesis, this suspects GEMIN4 variants role in CML [18], [19].

Our research aimed to investigate the association between rs636832 and rs2740348 SNVs of AGO1 gene and Gemin4 gene, respectively, and risk, progression, and response to treatment in CML Egyptian patients to clarify if they could be considered as one of biomarkers for diagnosis and targeted for therapy in CML disease.

\section{Materials and Methods}

Our case-control study enrolled 110 adult Egyptian newly diagnosed Philadelphia (Ph) (p210) positive CML cases. Patients with other myeloproliferative neoplasms or double malignancies were excluded from the study. They were selected from the cases consulted to Medical Oncology department, National Cancer Institute $(\mathrm{NCl})$ as well to Hematology Outpatient Clinic, Faculty of Medicine, Cairo University in the interval from February 2015 to July 2015 with 5 years follow-up.

All CML cases were picked out by following the diagnostic features of CML settled by the World Health Organization (WHO) guidelines 2015 [20]. They were exposed to detailed history taking, complete physical examination, routine baseline laboratory checks, complete blood count (CBC), coagulation profile, and chemistry profile. Bone marrow study (BM), FISH for t (9; 22), and reverse transcriptase quantitative polymerase chain reaction (PCR) for $B C R-A B L$ on peripheral blood (PB) or BM samples as well abdominal ultrasound (US) were performed to our patients.

The CML patient can be present in one of 3 stages; chronic phase (CP), accelerated phase $(\mathrm{AP})$, or blast phase (BP) that also known by blastic transformation and blastic crisis. CP is known by blast count less than $10 \%$ with the absence of defining features of AP and BP. AP is diagnosed by either one of the following: basophils $>20 \%$ in PB, blasts $=10-19 \%$ in $\mathrm{PB}$, and/or BM, persistent platelet count less than 100 independent to treatment, permanent thrombocytosis $>1000$ resistant to therapy, increase white blood cells $>10$, spleen size not-responding to therapy or cytogenetic clonal progression. BP is transformation of $\mathrm{CML}$ to acute leukemia and diagnosed by the presence of blast cells $>20 \%$ in PB and/or BM.

The response to treatment was evaluated first for complete hematological recovery by CBC each 2 weeks, then for complete cytogenetic resolution by FISH monitoring each other 3 months followed by quantitative RT-PCR every 3 months until complete molecular response.

Sokal and EUTOS scores were assessed by the clinical data at diagnosis previous to the beginning of therapy. Age, size of spleen, PB blasts, and platelet count were included in estimation of Sokal score. The score is divided into low-risk $(<0.8)$, intermediate-risk (0.8-1.2), while score $>1.2$ is considered as a high risk. EUTOS score was depended on the size of spleen and basophils \% in the PB. Patients were divided between low-risk and high-risk according to the score of either $<87$ or $\geq 87$, respectively [21].

One hundred and ten age, sex, and racematched healthy persons were enrolled as a control 
group. They were selected among normal subjects coming for a routine check-up with normal investigations and no history of CML or other medical diseases.

All subjects were included after they gave willingly informed consent to participate in the study. Protocol was handled in accordance to the Declaration of Helsinki that involves the ethics of human medical researches. The approval of the study was obtained by the Ethical Committee of Faculty of Medicine, Cairo University.

\section{Genotyping of rs636832 A/G and rs2740348}

$G / C$

\section{Extraction of genomic DNA}

Three-milliliter venous $\mathrm{PB}$ was collected on a sterile vacutainer tube containing $5 \%$ ethylene diamine tetra-acetic acid. Samples were kept at $-20^{\circ} \mathrm{C}$ to the time of DNA extraction. GeneJET ${ }^{\mathrm{TM}}$ DNA Purification Mini Kit (ThermoFisher, \# K0781) was used for DNA extraction according to instruction's procedure.

\section{SNP genotyping assay}

TaqMan SNP assay (Thermo Fisher; \#4351379) was utilized with context sequence for $r s 636832 \quad A / G$ of $A G O 1 ; \quad$ [VIC/FAM] TCTGATTCCAGAACATATCACTC CT[A/G] AAAGAAAGCCTGTATTCATTAGCAG. For rs2740348 G/C of GEMIN4; it was [VIC/FAM] A G CAGCCTCAACACCAAGTCTGGCT[C/G] TCGGAAGAGGGCCCTGTTACTCCCC.

\section{DNA amplification}

Thermo Fisher TaqMan ${ }^{\circledR}$ Genotyping Master Mix was in use (\#4371353). The final volume of PCR reaction was $20 \mu \mathrm{L} ; 3 \mathrm{ml}$ extracted DNA, $10 \mu \mathrm{L}$ Master Mix, $0.5 \mu \mathrm{L}$ SNP, and $6.5 \mu \mathrm{L}$ distilled water. The mixture was gently mixed and put on a real-time PCR Thermal Cycler (Step One apparatus; Applied Biosystems). Amplification program started by hold for $10 \mathrm{~min}$ at $95^{\circ} \mathrm{C}$ followed by 45 cycles; each processed as denaturation for $15 \mathrm{~s}$ at $95^{\circ} \mathrm{C}$ then annealing/extension for $1 \mathrm{~min}$ at $60^{\circ} \mathrm{C}$. Allelic and genotypic identification was done according to the plotted fluorescence signals.

\section{Statistical analysis}

Hardy-Weinberg equilibrium (HWE) was measured by a goodness-of-fit $\chi 2$ test. Data were evaluated using IBM SPSS advanced statistics version 20 (SPSS Inc., Chicago, IL). Mean and standard deviation (SD) used to demonstrate quantitative data. Qualitative data were expressed as frequency and percentage (\%). Chi-square test or Fisher's exact test was employed to examine the relations between qualitative variables. For quantitative data, two groups comparison was analyzed using Student's t-test while ANOVA test was operated for three groups' comparison. Risk estimation was expressed by odds ratio (OR) and 95\% confidence interval (Cl). Linkage disequilibrium (LD) was mathematically analyzed [22], [23]. CML patients' survival rates were detected using Kaplan-Meier method and Log Rank Test. A p $\leq 0.05$ was regarded as significant.

\section{Results}

\section{Demographic and clinical features}

Our CML cases were matched with the controls regarding age and sex with $p>0.05$. Most of our cases were in the chronic phase at presentation. Eutos and Sokal scores were calculated to CML cases at diagnosis before treatment beginning (Table 1).

Table 1: Demographic and clinical features

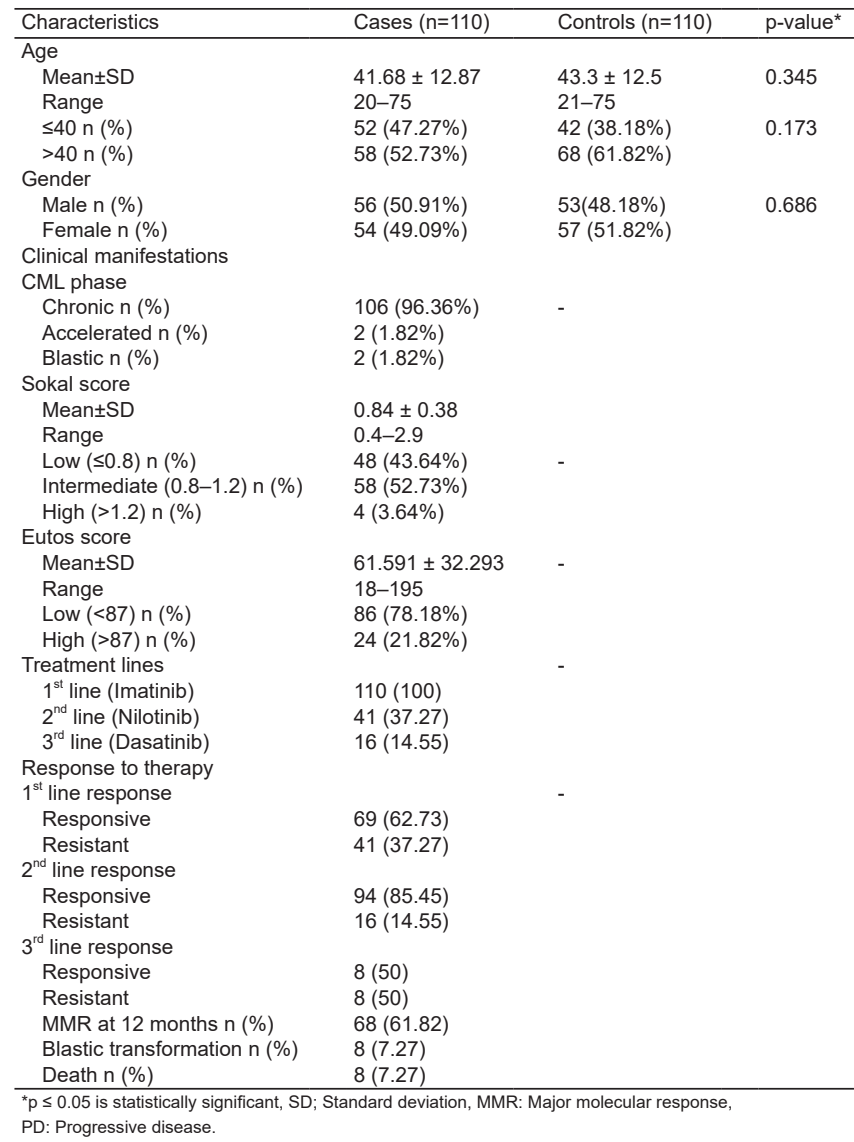

Our patients received Hydrea (3000 mg/day) at their initial presentation to control disease until Ministry of Health approval for TKIs. The first line of treatment was Imatinib at dose of $400 \mathrm{mg} /$ day. In resistance to $1^{\text {st }}$ line of treatment, shift to the $2^{\text {nd }}$ line in the form of Nilotinib $800 \mathrm{mg} /$ day was occurred that if failed to produce the optimal response; $3^{\text {rd }}$ line (Dasatinib) $100 \mathrm{mg} /$ day was started instead. On the regular follow-up to response to 
therapy, major molecular response (MMR) was detected in more than $50 \%$ of our cases. Blastic transformation was observed in 8 cases that ended by death in 3 patients from the total 8 deaths on follow-up (Table 1).

\section{Genotyping of AG01_rs636832 A/G and Gemin4_rs2740348 G/C}

The observed frequencies of genotypes of both SNVs were found to be concomitant to the expected under HWE in both case and controls with $p>0.05$ (Table 2).

Table 2: Genotypes and alleles frequencies of rs636832 and rs2740348 among cases and controls

\begin{tabular}{|c|c|c|c|c|c|c|}
\hline \multirow{2}{*}{ Characteristics } & \multicolumn{2}{|c|}{ Cases $(n=110)$} & \multicolumn{2}{|c|}{ Controls $(n=110)$} & \multirow{2}{*}{ OR $(95 \% \mathrm{Cl})$} & \multirow{2}{*}{ p-value ${ }^{*}$} \\
\hline & $\bar{n}$ & $\%$ & $\mathrm{n}$ & $\%$ & & \\
\hline \multicolumn{7}{|c|}{ AG01 rs636832 A/G } \\
\hline Genotypes & & & & & - & 0.389 \\
\hline AA & 5 & 4.55 & 2 & 1.82 & & \\
\hline$A G$ & 29 & 26.36 & 25 & 22.73 & & \\
\hline GG & 76 & 69.09 & 83 & 75.45 & & Reference \\
\hline$A A+A G$ & 34 & 30.91 & 27 & 24.55 & $\begin{array}{l}1.375 \\
(0.760-2.489)\end{array}$ & 0.293 \\
\hline \multicolumn{7}{|l|}{ Alleles } \\
\hline A & 39 & 17.73 & 29 & 13.18 & 1.419 & 0.189 \\
\hline G & 181 & 82.27 & 191 & 86.82 & $(0.842-2.391)$ & \\
\hline P HWE & 0.601 & & 0.997 & & & \\
\hline \multicolumn{7}{|c|}{ GEMIN4 rs2740348 G/C } \\
\hline Genotypes & & & & & - & Reference \\
\hline $\mathrm{CC}$ & 92 & 83.64 & 97 & 88.18 & & 0.435 \\
\hline GG & 1 & 0.91 & 0 & 0 & & \\
\hline $\mathrm{GC}$ & 17 & 15.45 & 13 & 11.82 & & \\
\hline$G G+G C$ & 18 & 16.36 & 13 & 11.82 & $\begin{array}{l}1.460 \\
(0.677-3.148)\end{array}$ & 0.355 \\
\hline \multicolumn{7}{|l|}{ Alleles } \\
\hline G & 19 & 8.64 & 13 & 5.91 & 1.505 & 0.273 \\
\hline C & 201 & 91.36 & 207 & 94.09 & $(0.724-3.129)$ & \\
\hline P HWE & 0.977 & & 0.909 & & & \\
\hline
\end{tabular}

No statistically significant difference was observed regarding the genotypic and allelic frequencies between cases and controls for both variants. Using Logistic regression analysis revealed that the rs636832 A/G and rs2740348 G/C genotypes were not significantly associated with CML risk (Table 2).

LD analysis of the two SNPs revealed that there was a modest LD between rs636832 A/G and rs2740348 G/C among CML cases with $p<0.001$, $D^{\prime}=0.51$, and $r^{2}=0.1$.

\section{patients}

\section{Genotypes and clinical criteria of CML}

For AG01 rs636832 A/G

GG genotype was the major homozygote genotype in our study. GG genotype in CML cases associated with male predominance even after sex stratification. Moreover, age stratification revealed that GG genotype was more overrepresented at younger age at diagnosis ( $\leq 40$ years) in $\mathrm{CML}$ cases (Table 3 and 5).

GG genotype was detected to be more prevalent in CML cases with higher bad prognostic grades of both Eutos and Sokal scores. GG genotype was found to be more evident in patients not achieving
MMR at 12 months than $A A$ and $A G$ genotypes or $(A A+A G)$ genotypes. $G G$ genotype compared to $(A A+A G)$ genotypes showed more existence in $C M L$ patients who had no response to the $1^{\text {st }}$ line of treatment with $p<0.05$ (Table 3).

No statistical significance was found in $\mathrm{CML}$ patients with genetic modalities of $\mathrm{rs} 636832 \mathrm{~A} / \mathrm{G}$ regarding $\mathrm{CML}$ phases, response to $2^{\text {nd }}$ and $3^{\text {rd }}$ lines of treatment as well to the progression to blastic phase (Table 3).

\section{For Gemin4_rs2740348 G/C}

CC genotype was the major homozygote genotype in our work. It was found after sex stratification to be less predominant in female $\mathrm{CML}$ cases in comparison to $\mathrm{GC}$ and $\mathrm{GG}$ as well as to $(\mathrm{GG}+\mathrm{GC})$ genotypes with $p=0.03$ and 0.009 , respectively. Higher levels of Eutos score were encountered in CC genotype than those observed in $(G G+G C)$ genotypes with $p$ value $=0.037$ (Tables 4 and 5).

CC genotype in comparison to $(G G+G C)$ genotypes was more presented in $\mathrm{CML}$ patients with suboptimal response at 12 months of therapy as well in unresponsive to $2^{\text {nd }}$ and $3^{\text {rd }}$ lines of TKIs with $p<0.05$ (Table 4).

No statistical significance was found in CML patients with different genetic types of rs2740348 $\mathrm{G} / \mathrm{C}$ regarding age, phases of the disease and grades of prognostic scores (Eutos and Sokal). In addition, no significant difference was detected regarding the progression to blastic transformation (Table 4).

\section{Overall survival (OS) of CML patients and genotyping}

Over 5 years follow-up, the number of deaths in genotypic analysis revealed no statistically significant difference for genotypic modalities in both variants (Tables 3 and 4). For AGO1_rs636832 A/G, the mean of $O S$ in $(A A+A G)$ and $G G$ were 59.82 and 57.19 months, respectively. While in Gemin4_rs2740348 G/C, the mean of $\mathrm{OS}$ in $(\mathrm{GG}+\mathrm{GC}), \overline{C C}$ was 58.3 and 57.95 months independently with $(p=0.238$ and 0.770 , respectively) (Figure 1).

\section{Discussion}

Although CML was the initial malignancy with a definitive chromosomal specification (Ph chromosome), many transformations were recognized in its pathogenesis [24]. There is increase evidence of the importance of miRs and their biogenesis as well binding site genes in the pathogenesis along with prognosis of hematological malignancies including CML [6]. 
Table 3: rs636832 genotypic variants compared to clinical criteria of CML patients

\begin{tabular}{|c|c|c|c|c|c|c|c|c|}
\hline \multirow[t]{3}{*}{ Characteristics } & \multicolumn{8}{|l|}{ AG01 rs636832 } \\
\hline & $\overline{\mathrm{AA}}$ & $\mathrm{AG}$ & GG & $p$-value ${ }^{*}$ & $\mathrm{AA}+\mathrm{AG}$ & $A A+A G$ & GG & $p$-value* \\
\hline & $\mathrm{n}(\%)$ & $\mathrm{n}(\%)$ & & & $\mathrm{n}(\%)$ & $\mathrm{n}(\%)$ & $\mathrm{n}(\%)$ & \\
\hline \multicolumn{9}{|l|}{ Sex } \\
\hline Male & $0(0)$ & $8(27.6)$ & $48(63.2)$ & \multirow[t]{2}{*}{$<0.001^{*}$} & $8(23.5)$ & $8(23.5)$ & $48(63.2)$ & \multirow[t]{2}{*}{$<0.001^{*}$} \\
\hline Female & $5(100)$ & $21(72.4)$ & $28(36.8)$ & & $26(76.5)$ & $26(76.5)$ & $28(36.8)$ & \\
\hline \multicolumn{9}{|l|}{ Age group } \\
\hline$\leq 40$ years & $2(40)$ & $11(37.9)$ & 39 (51.3) & \multirow[t]{2}{*}{0.445} & $13(38.2)$ & $13(38.2)$ & 39 (51.3) & \multirow[t]{2}{*}{0.204} \\
\hline$>40$ years & $3(60)$ & $18(62.1)$ & 37 (48.7) & & $21(61.7)$ & $21(61.7)$ & $37(48.7)$ & \\
\hline \multicolumn{9}{|l|}{ Phase of disease } \\
\hline Chronic & $5(100)$ & $28(96.55)$ & $73(96.05)$ & & $33(97.06)$ & $33(97.06)$ & $73(96.05)$ & \multirow[t]{2}{*}{0.794} \\
\hline Accelerated+ Blastic & $0(0)$ & $1(3.45)$ & $3(3.95)$ & 0.899 & $1(2.94)$ & $1(2.94)$ & $3(3.95)$ & \\
\hline \multicolumn{9}{|l|}{ Sokal score level } \\
\hline Mean \pm SD & $0.740 \pm 0.182$ & $0.741 \pm 0.331$ & $0.884 \pm 0.400$ & 0.19 & $0.741 \pm 0.312$ & $0.741 \pm 0.312$ & $0.884 \pm 0.400$ & 0.068 \\
\hline Low & $3(60)$ & 19 (65.5) & $26(34.2)$ & \multirow{3}{*}{$0.051^{*}$} & $22(64.7)$ & $22(64.7)$ & $26(34.2)$ & \multirow[t]{3}{*}{$0.011^{*}$} \\
\hline Intermediate & $2(40)$ & $9(31.0)$ & $47(61.8)$ & & $11(32.5)$ & $11(32.5)$ & $47(61.8)$ & \\
\hline High & $0(0)$ & $1(3.4)$ & $3(3.9)$ & & $1(2.9)$ & $1(2.9)$ & $3(3.9)$ & \\
\hline \multicolumn{9}{|l|}{ EUTOS score level } \\
\hline Mean \pm SD & $35.400 \pm 15.323$ & $44.448 \pm 29.484$ & $69.855 \pm 30.822$ & $<0.001^{*}$ & $43.118 \pm 27.868$ & $43.118 \pm 27.868$ & $69.855 \pm 30.822$ & $<0.001^{*}$ \\
\hline Low & $5(100)$ & $28(96.5)$ & $53(69.7)$ & \multirow[t]{2}{*}{$0.006^{*}$} & $33(97.1)$ & $33(97.1)$ & $53(69.7)$ & \multirow[t]{2}{*}{$0.001^{*}$} \\
\hline High & $0(0)$ & $1(3.4)$ & $23(30.2)$ & & $1(2.9)$ & $1(2.9)$ & $23(30.2)$ & \\
\hline \multirow{2}{*}{\multicolumn{9}{|c|}{$\begin{array}{l}\text { Treatment response } \\
1^{1^{t t}} \text { Line response (Imatinib) }\end{array}$}} \\
\hline & & & & & & & & \\
\hline Responsive & $1(20)$ & $7(24.1)$ & $33(43.4)$ & \multirow[t]{2}{*}{0.135} & $8(23.5)$ & $8(23.5)$ & $33(43.4)$ & \multirow[t]{2}{*}{$0.046^{*}$} \\
\hline Resistant & $4(80)$ & $22(75.86)$ & $43(56.58)$ & & $26(76.47)$ & $26(76.47)$ & $43(56.58)$ & \\
\hline \multicolumn{9}{|l|}{$2^{\text {nd }}$ line response (Nilotinib) } \\
\hline Responsive & $0(0)$ & $3(10.3)$ & $13(17.1)$ & \multirow[t]{2}{*}{0.435} & $3(8.8)$ & $3(8.8)$ & $13(17.1)$ & \multirow[t]{2}{*}{0.255} \\
\hline Resistant & $5(100)$ & $26(89.7)$ & 63 (82.9) & & 31 (91.2) & $31(91.2)$ & 63 (82.9) & \\
\hline \multicolumn{9}{|c|}{$3^{\text {rd }}$ Line response (Dasatinib) } \\
\hline Responsive & $0(0)$ & $2(66.7)$ & $6(46.15)$ & \multirow[t]{2}{*}{0.522} & $2(66.67)$ & $2(66.67)$ & $6(46.15)$ & \multirow[t]{2}{*}{0.522} \\
\hline Resistant & $0(0)$ & $1(33.3)$ & $7(53.85)$ & & $1(33.33)$ & 1 (33.33) & $7(53.85)$ & \\
\hline MMR at 12 months & $4(80.0)$ & $25(86.2)$ & $39(51.3)$ & $0.003^{*}$ & $29(85.3)$ & $29(85.3)$ & $39(51.3)$ & $0.001^{*}$ \\
\hline Blastic transformation & $0(0.0)$ & $1(3.4)$ & $7(9.2)$ & 0.486 & $1(2.9)$ & $1(2.9)$ & $7(9.2)$ & 0.242 \\
\hline Death & $0(0.0)$ & $1(3.4)$ & $7(9.2)$ & 0.486 & $1(2.9)$ & $1(2.9)$ & $7(9.2)$ & 0.242 \\
\hline
\end{tabular}

Table 4: rs2740348 genotypic variants compared to clinical criteria of CML patients

\begin{tabular}{|c|c|c|c|c|c|c|c|}
\hline \multirow[t]{3}{*}{ Characteristics } & \multicolumn{7}{|c|}{ Gemin4 rs2740348 } \\
\hline & $\overline{G G}$ & $\mathrm{GC}$ & $\mathrm{CC}$ & $p$-value ${ }^{*}$ & $G G+G C$ & $\mathrm{CC}$ & $p$-value ${ }^{*}$ \\
\hline & $\bar{N}(\%)$ & $\mathrm{N}(\%)$ & $\mathrm{N}(\%)$ & & $\mathrm{N}(\%)$ & $\mathrm{N}(\%)$ & \\
\hline \multicolumn{8}{|l|}{$\overline{\text { Sex }}$} \\
\hline Male & $0(0)$ & $6(35.3)$ & $50(54.3)$ & 0.209 & $6(33.3)$ & $50(54.3)$ & 0.103 \\
\hline Female & $0(0)$ & $11(64.7)$ & $42(45.6)$ & & $12(66.7)$ & $42(45.6)$ & \\
\hline \multicolumn{8}{|l|}{ Age group } \\
\hline$\leq 40$ years & $0(0)$ & $8(47.1)$ & $44(47.8)$ & 0.635 & $8(44.4)$ & $44(47.8)$ & 0.793 \\
\hline$>40$ years & $1(100)$ & $9(52.9)$ & $48(52.2)$ & & $10(55.6)$ & $48(52.2)$ & \\
\hline \multicolumn{8}{|l|}{ Phase of disease } \\
\hline Chronic & $1(100)$ & $16(94.12)$ & $89(96.74)$ & 0.852 & $17(94.44)$ & $89(96.74)$ & 0.634 \\
\hline Accelerated+ Blastic & $0(0)$ & $1(5.88)$ & $3(3.26)$ & & $1(5.56)$ & $3(3.26)$ & \\
\hline \multicolumn{8}{|l|}{ Sokal score level } \\
\hline Mean \pm SD & $0.8 \pm 0$ & $0.735 \pm 0.401$ & $0.860 \pm 0.377$ & 0.464 & $0.739 \pm 0.390$ & $0.860 \pm 0.377$ & 0.218 \\
\hline Low & $0(0)$ & $11(64.7)$ & $37(40.2)$ & 0.272 & $11(61.1)$ & $37(40.2)$ & 0.196 \\
\hline Intermediate & $1(100)$ & $5(29.4)$ & $52(56.5)$ & & $6(33.3)$ & $52(56.5)$ & \\
\hline High & $0(0)$ & $1(5.9)$ & $3(3.3)$ & & $1(5.6)$ & $3(3.3)$ & \\
\hline \multicolumn{8}{|l|}{ EUTOS score level } \\
\hline Mean + SD & $29 \pm 0$ & $48.176 \pm 39.695$ & $64.424 \pm 30.310$ & 0.097 & $47.111 \pm 38.774$ & $64.424 \pm 30.310$ & $0.037^{*}$ \\
\hline Low & $1(100.0)$ & $15(88.2)$ & $70(76.1)$ & 0.467 & $16(88.9)$ & $70(76.1)$ & 0.229 \\
\hline High & $0(0.0)$ & $2(11.8)$ & $22(23.9)$ & & $2(11.1)$ & $22(23.9)$ & \\
\hline \multirow{2}{*}{\multicolumn{8}{|c|}{$\begin{array}{l}\text { Treatment response } \\
1^{\text {st }} \text { Line response (Imatinib) }\end{array}$}} \\
\hline & & & & & & & \\
\hline Responsive & $0(0.0)$ & $1(5.9)$ & $40(43.5)$ & $0.010^{*}$ & $1(5.6)$ & $40(43.5)$ & $0.002^{*}$ \\
\hline \multirow{2}{*}{\multicolumn{8}{|c|}{$\begin{array}{l}\text { Resistant } \\
2^{\text {nd }} \text { line response (Nilotinib) }\end{array}$}} \\
\hline & & & & & & & \\
\hline Responsive & $0(0.0)$ & $0(0.0)$ & $16(17.4)$ & 0.16 & $0(0.0)$ & $16(17.4)$ & $0.056^{*}$ \\
\hline \multirow{2}{*}{\multicolumn{8}{|c|}{$3^{\text {rd }}$ Line response (Dasatinib) }} \\
\hline & & & & & & & \\
\hline Responsive & $0(0)$ & $0(0)$ & $8(50)$ & - & $2(66.67)$ & $6(46.15)$ & 0.522 \\
\hline Resistant & $0(0)$ & $0(0)$ & $8(50)$ & & $1(33.33)$ & $7(53.85)$ & \\
\hline MMR at 12 months & $1(100.0)$ & $14(82.3)$ & $53(57.6)$ & 0.114 & $15(83.3)$ & $53(57.6)$ & $0.040^{*}$ \\
\hline Blastic transformations & $0(0.0)$ & $2(11.8)$ & $6(6.5)$ & 0.717 & $2(11.1)$ & $6(6.5)$ & 0.493 \\
\hline Death & $0(0.0)$ & $1(5.9)$ & $7(7.6)$ & 0.931 & $1(5.6)$ & $7(7.6)$ & 0.759 \\
\hline
\end{tabular}

miRs are essential epigenetic regulators of genetic expression directly by transcription inhibition, mRNA degradation, or indirectly activate expression of mRNA by cleavage their inhibitors. They affect $80 \%$ of cellular transcriptome to be essential in the regulation of cellular properties of apoptosis, differentiation, and proliferation [7].

AGO1 and GEMIN4 are essential proteins of miRISC. miRISC has a function as oncogenes or tumor suppressor genes in carcinogenesis [25]. AGO1 and
GEMIN4 genetic variants play an important role in the development and prognosis of multiple tumors. AGO1 rs636832 SNV was detected to be related to lung cancer risk, gastric carcinoma metastasis [10], [11]. GEMIN4 rs2740348 variants were found to affect the severity of prostatic cancer as well the risk of bladder cancer and renal cell carcinoma [12], [26], [27].

Ourstudy confirmed the importance of rs 636832 $\mathrm{A} / \mathrm{G}$ and $\mathrm{rs} 2740348 \mathrm{G} / \mathrm{C}$ of microRNA biogenesis genes (AGO1 and GEMIN4, respectively) in prognosis and 
Table 5: Sex and age stratification for rs636832 and rs2740348

\begin{tabular}{|c|c|c|c|c|c|c|c|c|c|c|c|c|}
\hline \multicolumn{7}{|l|}{ Sex stratification } & \multicolumn{6}{|c|}{ Age stratification } \\
\hline \multirow[t]{3}{*}{ Characteristics } & \multicolumn{3}{|l|}{ Male } & \multicolumn{2}{|l|}{ Female } & \multirow[b]{2}{*}{ p-value ${ }^{*}$} & \multicolumn{3}{|l|}{$\leq 40$ Years } & \multicolumn{3}{|l|}{$>40$ Years } \\
\hline & $\begin{array}{l}\text { Controls } \\
(n=53)\end{array}$ & $\begin{array}{l}\text { Cases } \\
(n=56)\end{array}$ & $p$-value ${ }^{*}$ & Cases $(n=54)$ & Controls $(n=57)$ & & Case $(n=52)$ & Controls $(n=42)$ & $p$-value ${ }^{\star}$ & Case $(n=58)$ & Control $(n=68)$ & $p$-value ${ }^{*}$ \\
\hline & $\mathrm{n}(\%)$ & $\mathrm{n}(\%)$ & & $\mathrm{n}(\%)$ & $\mathrm{n}(\%)$ & & $\mathrm{n}(\%)$ & $\mathrm{n}(\%)$ & & $\mathrm{n}(\%)$ & $\mathrm{n}(\%)$ & \\
\hline \multicolumn{13}{|l|}{ AG01 rs636832 } \\
\hline GG & $36(67.92)$ & $48(85.7)$ & Reference & $28(51.8)$ & $47(82.46)$ & Reference & $39(75.0)$ & $28(66.7)$ & Reference & $37(63.8)$ & $55(80.88)$ & Reference \\
\hline AA & $0(0.0)$ & $0(0.0)$ & $0.027^{\star}$ & $5(9.3)$ & $2(3.5)$ & $0.003^{*}$ & $2(3.8)$ & $2(4.8)$ & 0.672 & $3(5.2)$ & $0(0.0)$ & $0.037^{*}$ \\
\hline$A G$ & $17(32.08)$ & $8(14.3)$ & & $21(38.9)$ & $8(14.04)$ & & $11(21.1)$ & $12(28.6)$ & & $18(31.0)$ & $13(19.12)$ & \\
\hline$A A+A G$ & $17(32.08)$ & $8(14.3)$ & $0.027^{*}$ & $26(48.1)$ & $10(17.54)$ & $0.001^{*}$ & $13(25.0)$ & $14(33.3)$ & 0.375 & $21(36.2)$ & $13(19.12)$ & $0.031^{*}$ \\
\hline \multicolumn{13}{|c|}{ GEMIN4 rs2740348 } \\
\hline $\mathrm{CC}$ & $43(81.13)$ & $50(89.3)$ & Reference & $42(77.8)$ & $54(94.74)$ & Reference & $44(84.6)$ & $34(80.9)$ & Reference & $48(82.8)$ & $63(92.65)$ & Reference \\
\hline GC & $10(18.87)$ & $6(10.7)$ & 0.229 & $11(20.4)$ & $3(5.26)$ & $0.030^{*}$ & $8(15.4)$ & $8(19.0)$ & 0.638 & $9(15.5)$ & $5(7.35)$ & 0.183 \\
\hline GG & $0(0.0)$ & $0(0.0)$ & & $1(1.8)$ & $0(0.0)$ & & $0(0.0)$ & $0(0.0)$ & & $1(1.7)$ & $0(0.0)$ & \\
\hline$G G+G C$ & $10(18.87)$ & $6(10.7)$ & 0.229 & $12(22.2)$ & $3(5.26)$ & $0.009^{*}$ & $8(15.4)$ & $8(19.0)$ & 0.638 & $10(17.2)$ & $5(7.35)$ & 0.088 \\
\hline
\end{tabular}

\section{Survival Functions}

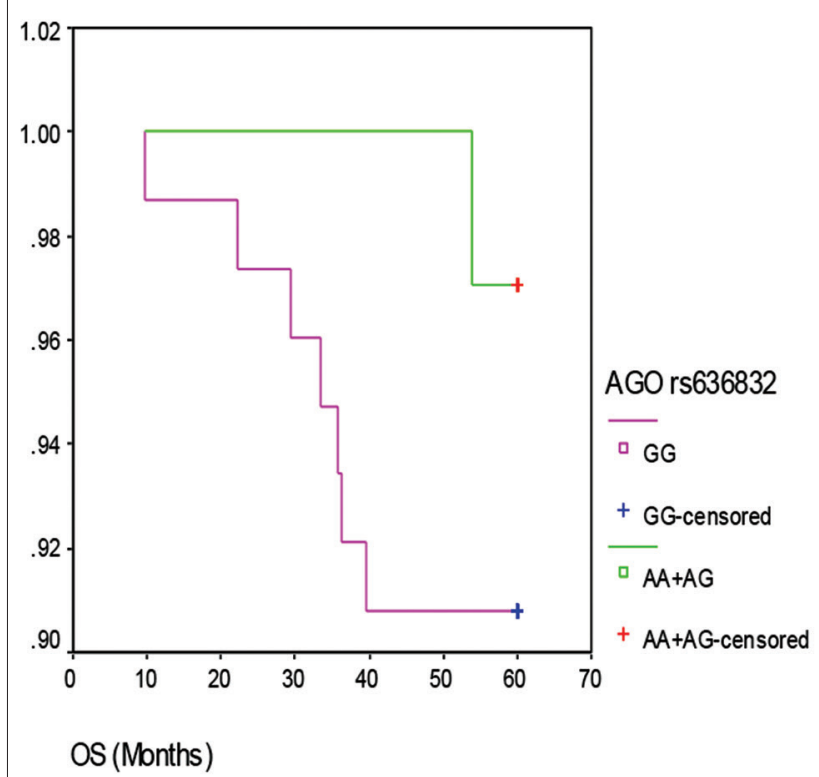

Figure 1: Overall survival regarding AGO1 and GEMIN4 genotypes

\section{Survival Functions}

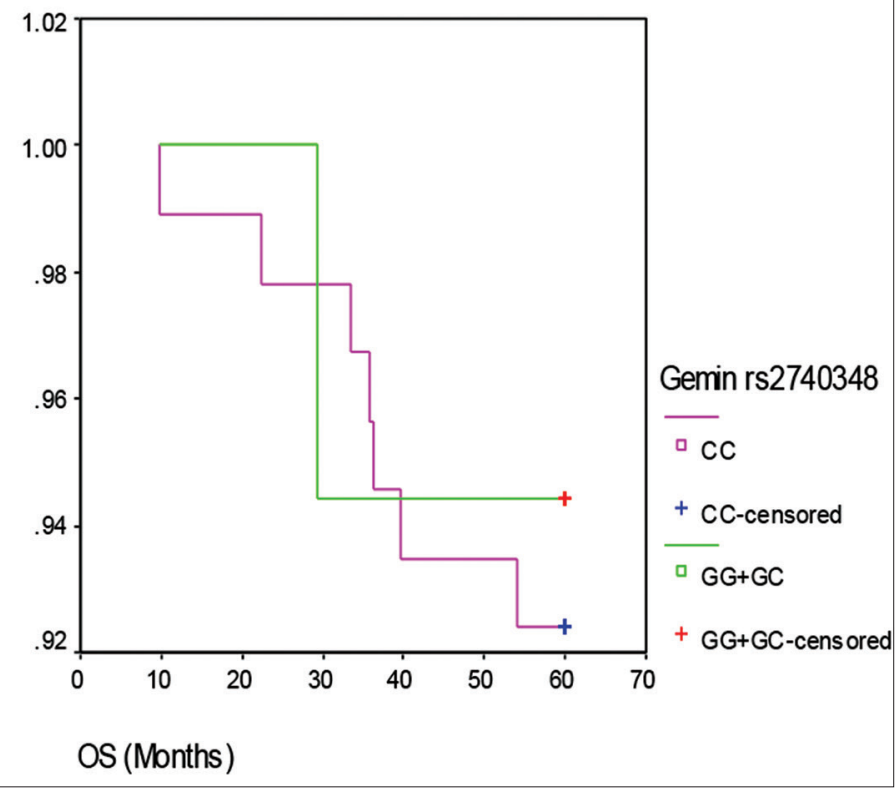

response to therapy of Egyptian CML patients as GG genotype of rs636832 and CC genotypes of rs 2740348 were appeared to be correlated with the bad clinical prognostic scores as well linked to the resistance to TKIs therapy. Hence, they can be implanted for prognosis prediction as well for the targeted therapy in CML disease.

Regarding AG01_rs636832, our results revealed no a significance difference between the cases and controls as regard the frequencies for $\mathrm{AA}$ and $(A G+G G)$ genotypes $(p=0.293, O R=1.375$, and $95 \%$ $\mathrm{Cl}=0.760-2.489)$ as well for $A$ and $\mathrm{G}$ alleles $(p=0.189$, $\mathrm{OR}=1.419$, and $95 \% \mathrm{Cl}=0.842-2.391)$. In respect to rs2740348, the frequencies for CC and (CG+GG) genotypes, as well $C$ and $G$ alleles frequencies in our cases showed no a statistically significance difference from their frequencies in the controls $(p=0.355$, $\mathrm{OR}=1.460$, and $95 \% \mathrm{Cl}=0.677-3.148)$ and $(\mathrm{p}=0.273$, $\mathrm{OR}=1.505$, and $95 \% \mathrm{Cl}=0.724-3.129$ ), respectively.

Modest LD between both variants was detected in CML patients with $p<0.001$. LD is referred to non-random association of alleles at two or more chromosomes not necessary to be on the same chromosome that leads to the SNV alleles to be inherited together [22].

In consistent to our results, Gutiérrez-Malacatt et al. [9] investigated $312 \mathrm{CML}$ patients and 487 healthy controls for rs 636832 and rs 2740348 by real-time PCR confirmation of their result was done by sequencing of $10 \%$ of their analyzed samples. Regarding rs636832, they found that the frequencies of $A A, A G$, and $G G$ in cases were $0.23,0.5$, and 0.27 near to that in controls $0.26,0.49$, and 0.25 , respectively. There was no a statistically significance difference in comparing $A G$ to AA $(p=0.44$ and $\mathrm{OR}[95 \% \mathrm{Cl}]=1.15[0.81-1.64])$ as well as in comparing GG to AA ( $p=0.35$ and OR [95\% $\mathrm{Cl}]=1.21[0.81-1.81])$. Their allelic $A$ and $G$ frequencies were found to be in controls 0.5 and 0.49 similar to that in cases 0.48 and 0.52 independently with $(p=0.35$ and OR $[95 \% \mathrm{Cl}]=1.10[0.90-1.35])$.

In addition, regarding rs2740348 GutiérrezMalacatt et al. [9] reported the frequencies of GG, GC, and CC genotypes in controls were $0.62,0.35$, and 0.04 and in cases were $0.65,0.3$, and 0.04 , respectively. No 
a statistically significance was found in comparison of CC to $G G$ as well GC to GG genotypes ( $p=0.66$ and OR $[95 \% \mathrm{Cl}]=1.18[0.57-2.44])$ and $(p=0.26$ and OR $[95 \% \mathrm{Cl}]=0.84[0.61-1.14])$ individually. Allelic $\mathrm{G}$ and $\mathrm{C}$ were 0.79 and 0.21 in controls and 0.8 and 0.2 in cases, respectively, with $(p=0.57$ and OR $[95 \% \mathrm{Cl}]=0.93$ [0.72-1.20]).

Our results revealed that GG genotype in CML cases showed male predominance compared to $A A$ and $A G$ or to $(A A+A G)$ with $p<0.001$. After sex stratification, GG genotype showed higher frequencies in male cases than in male controls with $p=0.027$. Furthermore, our female cases showed less frequencies of CC genotype of rs2740348 than found in female controls with $p=0.03$.

In contrast to our finding, Gutiérrez-Malacatt et al. [9] showed that frequencies of $A A, A G$, and GG genotypes in male controls $0.23,0.53$, and 0.24 were near to it in male cases $0.26,0.5$, and 0.24 , respectively. There was no statistical significance in the comparison of $G G$ to $A A$ or $A G$ to $A A$ genotypes with $p=0.78$ and 0.49 independently. Furthermore, for rs2740348, they found the frequencies of GG, GC, and $C C$ in female CML cases to be $0.68,0.27$, and 0.05 , while in female controls were $0.64,0.33$, and 0.03 , respectively, with $p$ value on comparison of $C C$ to $G G$ and $G C$ to $G G$ genotypes were 0.37 and 0.29 , respectively.

Furthermore, our cases after age stratification showed that GG genotype of rs636832 was more presented at younger age at diagnosis ( $<40$ years) in cases than controls with $p=0.037$ that was not obvious in rs2740348 ( $p=0.183)$. This augments bad prognostic value of rs636832 in CML patients. Gutiérrez-Malacatt et al. [9] did not correlate the genotype frequencies with the age of their patients.

No statistical significance was found in our CML patients with genetic modalities of both variants regarding the phase of disease ( $C P$ vs. AP/BP). In homogenous to our results, Gutiérrez-Malacatt et al. [9] showed no difference in genotypic frequencies of both variants between early $C M L$ disease $(C P)$ and late stage (AP/BP). In rs636832, frequencies of $A A, A G$, and $G G$ genotypes in $C P$ were $0.26,0.48$, and 0.26 and in AP/BP were $0.15,0.63$, and 0.22 , respectively, with $p=0.56$ and 0.17 in comparing $G G$ to $A A$ and $A G$ to AA genotypes respectively. As well for rs2740348, the frequencies for CC, GC, and GG genotypes showed no statistically significant difference between $\mathrm{CML}$ phases with $p>0.05$.

Regarding the prognostic clinical scores of our CML cases, GG genotype of rs636832 was found to be related to high grades of Sokal and Eutos compared to $(A A+A G)$ genotypes with $p=0.011$ and 0.001 individually. As well, CC genotype of rs2740348 compared to $(G G+G C)$ showed high levels of Eutos score with $p=0.037$. Gutiérrez-Malacatt et al. [9] did not relate the genotypic modalities of both variants to
CML prognostic scores. We are the first to demonstrate these relations.

In respect to the therapeutic response in our CML cases, GG genotype of rs636832 compared to $(A A+A G)$ genotypes was found to be overexpressed in $\mathrm{CML}$ cases that resistant to the $1^{\text {st }}$ line therapy as well in those who failed to obtain MMR at 12 months of treatment with $p=0.046$ and 0.001 , respectively. Similarly, CC genotype of rs2740348 compared to (GG+GC) was overrepresented in CML cases that exhibited resistance to the $1^{\text {st }}$ and $2^{\text {nd }}$ line therapy as well in those did not reach the MMR at 1 year of therapy with $p=0.002,0.056$, and 0.040 independently. No statistical significance between the genetic modalities of both variants regarding response to $3^{\text {rd }}$ line therapy, blastic transformation as well to OS of CML patients. In addition, no significant difference between the genetic modalities of rs636832 for the response to $2^{\text {nd }}$ line therapy with $p>0.05$.

In opposite to our results, Gutiérrez-Malacatt et al. [9] found no difference in response to Imatinib in both variants. As in rs636832, the frequencies of $\mathrm{AA}, \mathrm{AG}$, and $\mathrm{GG}$ in responsive were $0.24,0.45$, and 0.3 and in resistant were $0.23,0.56$, and 0.21 with $p=$ 0.56 and 0.51 in comparison $G G$ to $A A$ and $A G$ to $A A$ genotypes, respectively. Furthermore, in rs2740348, the frequencies of $\mathrm{GG}, \mathrm{GC}$ and $\mathrm{CC}$ in responsive were $0.64,0.32$, and 0.05 and in resistant were $0.66,0.29$, and 0.05 with p-value 0.98 and 0.74 in comparing $C C$ to GG and GC to GG genotypes, respectively. However, they did not follow-up their resistant patients on the other lines of treatment as well at different intervals of routine follow-up therapy. Our study is the initial research to document these finding.

Their opposite results to our study may be related to ethnic difference as well to that the major homozygous genotypes of both variants in our population were different than that found in MexicanMestizos ethnic of the case-control study of GutiérrezMalacatt et al. [9]. The major homozygous genotypes of rs636832 and rs2740348 in our study were GG and CC, while in Gutiérrez-Malacatt et al. were AG and GG, respectively.

AG01_rs636832 is an intronic un-translated variant that modifies the DNA three-dimensional structure and function with change in AGO1 expression. This affects the optimal production and action of various miRs with subsequent linkage to risk and prognosis of multiple diseases [28]. AGO1_rs636832 interacts through Wnt pathway that is essential in cancer development and prognosis. In addition, AGO1 regulates the transcription activity by stimulation of $\mathrm{PI} 3 \mathrm{~K}$ signaling [14]. Wnt pathway through PI3K signaling is involved in CML progression and therapeutic resistance [15]. This can give the basis of considering rs636832 as a bad prognostic as well poor therapeutic marker of $\mathrm{CML}$ in the present study. 
GEMIN4 rs2740348 is an exonic nonsynonymous variation (Gln439Glu). It is an important component of miRISC that plays a pivotal role in carcinogenesis. GEMIN4 expression is related to the biogenesis of its linked miRs that affect cancer risk and prognosis [13]. GEMIN4 interacts through MR receptor [25]. MR receptor is a target of GAL1 protein which is a bad prognostic marker for CML [18], [19]. This supports the prevalence of rs2740348 in the poor clinical scores and therapeutic resistance in our study.

In homogenous to our finding, Song et al. investigated rs636832 to gastric cancer. They revealed that the AA genotype and $A$ allele had a reduced risk of lymphatic metastasis of gastric cancer with no association to its risk [10]. Furthermore, Horikawa et al. 2008 documented no risk of rs636832 to renal carcinoma [12]. Discordant to the present study, Kim et al. found that the rs636832 AG or GG genotype has a lower risk to lung cancer than the AA genotype [11].

In contrast to our finding, Zhu et al., metaanalysis documented that $\mathrm{GC}+\mathrm{CC}$ genotypes associated with increased risk to cancer [29]. The absence of risk association to CML to rs2740348 in our study can be explained by the predominance of CC genotype as a major homogenous genotype in our study was with the presence of GG genotype in only one CML case.

It has been found that GC genotype of rs2740348 was related to the increased risk of cancer prostate and cancer breast [12], [26]. However, renal carcinoma risk has been decreased with the combined GC+CC genotypes as well with GC genotype in the haplotype representation of GEMIN4 gene [12].

The variability in the findings of researches regarding these variants may be related to the ethnic difference, the discrete malignancy criteria in each variant, as well presence of other associated natural factors and linked genotypes with cancer risk contribution. Further researches are required to allow their efficient evaluation in different malignancies.

We faced some limitations due to the lack of the financing to do another confirming method of our results, but we relayed on its analysis in other nations studies by sequencing. Our study contributes an important role in clarifying the relationships between microRNA biogenesis genes and CML in Egyptian population.

\section{Conclusion}

Our study demonstrates the first record of an association between rs636832 and rs2740348 variants and prognosis of CML disease. The rs636832 GG and rs2740348 CC genotypes are associated with poor clinical prognostic scores and linked to the resistance to TKIs therapy. No association between CML risk and both variants.

\section{References}

1. Edatharaa PM, Gorreb $M$, Kagitac S, Cingeethamd A Annamanenia S, Digumartic R, et al. Influence of caspase-9 polymorphisms on the development of chronic myeloid leukemia-a case-control study. Gene. 2019;1:100002. https:// doi.org/10.1016/j.gene.2018.100002

2. Hoffmann VS, Baccarani M, Hasford J, Lindoerfer D, Burgstaller S, Sertic D, et al. The EUTOS population-based registry: Incidence and clinical characteristics of 2904 CML patients in 20 European countries. Leukemia. 2015;29(6):133643. https://doi.org/10.1038/leu.2015.73

3. Siegel RL, Miller KD, Jemal A. Cancer statistics, 2018. CA Cancer J Clin. 2018;68(1):7-30.

PMid:29313949

4. World Health Organization. Egypt-global Cancer Observatory Geneva: World Health Organization; 2019. p. 1-2. Available from: https://gco.iarc.fr/today/data/factsheets/populations/818egypt-fact-sheets.pdf.

5. Bruzzoni-Giovanelli H, González JR, Sigaux F, Villoutreix BO, Cayuela JM, Guilhot J, et al. Genetic polymorphisms associated with increased risk of developing chronic myelogenous leukemia. Oncotarget. 2015;6(34):36269-77. https://doi.org/10.18632/ oncotarget.5915

PMid:26474455

6. Dzikiewicz-Krawczyk A. MicroRNA polymorphisms as markers of risk, prognosis and treatment response in hematological malignancies. Crit Rev Oncol Hematol. 2015;93(1):1-17. https:// doi.org/10.1016/j.critrevonc.2014.08.006

PMid:25217091

7. Alves R, Gonçalves AC, Jorge J, Marques G, Luís D, Ribeiro AB et al. MicroRNA signature refine response prediction in CML. Sci Rep. 2019;9:9666. https://doi.org/10.1038/s41598-019-46132-9

8. Arribas-Hernández L, Kielpinski LJ, Brodersen P. mRNA decay of most arabidopsismiRNA targets requires slicer activity of AGO1. Plant Physiol. 2016;171(4):2620-32. https://doi. org/10.1104/pp.16.00231

PMid:27208258

9. Gutiérrez-Malacatt $H$, Ayala-Sanchez $M$, Aquino-Ortega $X$ Dominguez-Rodriguez J, Martinez-Tovar A, Olarte-Carrillo I, et al. The rs61764370 functional variant in the KRAS oncogene is associated with chronic myeloid leukemia risk in women. Asian Pac J Cancer Prev. 2016;17(4):2265-70. https://doi. org/10.7314/apjcp.2016.17.4.2265

PMid:27221928

10. Song $\mathrm{X}$, Zhong $\mathrm{H}$, Wu $\mathrm{Q}$, Wang $\mathrm{M}$, Zhou J, Zhou $\mathrm{Y}$, et al. Association between SNPs in microRNA machinery genes and gastric cancer susceptibility, invasion, and metastasis in Chinese Han population. Oncotarget. 2017;8(49):86435-46. https://doi.org/10.18632/oncotarget.21199 PMid:29156806

11. Kim JS, Choi Y, Jin G, Kang HG, Choi JE, Jeon HS, et al. Association of a common AGO1 variant with lung cancer risk: A two-stage case-control study. Mol Carcinog. 2010;49(10):91321. https://doi.org/10.1002/mc.20672

PMid:20721975

12. Horikawa $\mathrm{Y}$, Wood CG, Yang $\mathrm{H}$, Zhao $\mathrm{H}, \mathrm{Ye} \mathrm{Y}, \mathrm{Gu}$ J, et al. 
Single nucleotide polymorphisms of microRNA machinery genes modify the risk of renal cell carcinoma. Clin Cancer Res. 2008;14(23):7956-62. https://doi.org/10.1158/1078-0432. ccr-08-1199

PMid: 19047128

13. Bermisheva MA, Takhirova ZR, Gilyazova IR, Khusnutdinova EK. MicroRNAbiogenesispathwaygenepolymorphismsareassociated with breast cancer risk. Hum Genat. 2018;54(5):568-75. https:// doi.org/10.1134/s1022795418040051

14. Wu G, Fan F, Hu P, Wang C. AGO1 enhances the proliferation and invasion of cholangiocarcinoma via the EMT-associated TGF- $\beta$ signaling pathway. Am J TransI Res. 2020;12(6):2890-902. PMid:32655817

15. Grassi S, Palumbo S, Mariotti V, Liberati D, Guerrini F, Ciabatti E, et al. The WNT pathway is relevant for the BCR-ABL1independent resistance in chronic myeloid leukemia. Front Oncol. 2019;9:532. https://doi.org/10.3389/fonc.2019.00532 PMid:31293972

16. Bibi S, Arslanhan MD, Langenfeld F, Jeanningros S, CernyReiterer S, Hadzijusufovic E, et al. Co-operating STAT5 and AKT signaling pathways in chronic myeloid leukemia and mastocytosis: Possible new targets of therapy. Haematologica. 2014;99(3):417-29. https://doi.org/10.3324/ haematol.2013.098442 PMid:24598853

17. Yang J, Fuller PJ, Morgan J, Shibata H, Clyne CD, Young MJ GEMIN4 functions as a coregulator of the mineralocorticoid receptor. J Mol Endocrinol. 2015;54:149-60. https://doi. org/10.1530/jme-14-0078

PMid:25555524

18. Luo $\mathrm{W}$, Song $\mathrm{L}$, Chen $\mathrm{XL}$, Zeng $\mathrm{XF}$, Wu JZ, Zhu CR, et al. Identification of galectin-1 as a novel mediator for chemoresistance in chronic myeloid leukemia cells. Oncotarget. 2016;7(18):26709-23. https://doi.org/10.18632/ oncotarget. 8489

PMid:27050374

19. Su YL, Luo HL, Huang CC, Liu TT, Huang EY, Sung MT, et al. Galectin-1 overexpression activates the FAK/PI3K/AKT/ mTOR pathway and is correlated with upper urinary urothelial carcinoma progression and survival. Cells. 2020;9(4):806. https://doi.org/10.3390/cells9040806

PMid:32225123

20. Hochhaus A, Saussele S, Rosti G, Mahon FX, Janssen JJ, Hjorth-Hansen $\mathrm{H}$, et al. Chronic myeloid leukaemia: ESMO clinical practice guidelines for diagnosis, treatment and follow-up. Ann Oncol. 2018;29(4):iv261. PMid:28881915

21. Baba SM, Shah ZA, Javaid K, Pandith AA, Rasool J,
Geelani SA, et al. Methylene tetrahydrofolate reductase gene C677T and A1298C polymorphic sequence variations influences the susceptibility to chronic myeloid leukemia in Kashmiri population. Front Oncol. 2019;24(9):612. https://doi. org/10.3389/fonc.2019.00612

PMid:31396477

22. Zapata C. Linkage disequilibrium measures for fine-scale mapping of disease loci are revisited. Front Genet. 2013;4:228. https://doi.org/10.3389/fgene.2013.00228

PMid:24204380

23. Berger $S$, Schlather $M$, de los Campos $G$, Weigend $S$, Preisinger R, Erbe $\mathrm{M}$, et al. A scale-corrected comparison of linkage disequilibrium levels between genic and non-genic regions. PLoS One. 2015;10(10):e0141216. https://doi. org/10.1371/journal.pone.0141216

PMid:26517830

24. Thompson PA, Kantarjian HM, Cortes JE. Diagnosis and treatment of chronic myeloid leukemia in 2015. Mayo Clin Proc. 2015;90(10):1440-54. https://doi.org/10.1016/j. mayocp.2015.08.010 PMid:26434969

25. Fang X, Yin Z, Li X, Xia L, Zhou B. Polymorphisms in GEMIN4 and AGO1 genes are associated with the risk of lung cancer: A case-control study in Chinese female non-smokers. Int J Environ Res Public Health. 2016;13(10):939. https://doi. org/10.3390/ijerph13100939 PMid:27669275

26. Liu J, Liu J, Wei M, He Y, Liao B, Liao G, et al. Genetic variants in the MicroRNA machinery gene GEMIN4 are associated with risk of prostate cancer: A case-control study of the Chinese Han population. DNA Cell Biol. 2012;31(7):1296-302. https://doi. org/10.1089/dna.2011.1600

PMid:22506892

27. Yang H, Dinney CP, Ye Y, Zhu Y, Grossman HB, Wu X. Evaluation of genetic variants in microRNA related genes and risk of bladder cancer. Cancer Res. 2008;68(7):2530-7. https:// doi.org/10.1158/0008-5472.can-07-5991 PMid:18381463

28. He $\mathrm{Y}$, Zhou $\mathrm{Y}, \mathrm{Xi} \mathrm{Q}$, Cui H, Luo $\mathrm{T}$, Song $\mathrm{H}$, et al. Genetic variations in MicroRNA processing genes are associated with susceptibility in depression. DNA Cell Biol. 2012;31(9):1499506. https://doi.org/10.1089/dna.2012.1660 PMid:22694265

29. Zhu W, Zhao J, He J, Qi D, Wang L, Ma X, et al. Genetic variants in the MicroRNA biosynthetic pathway Gemin3 and Gemin4 are associated with a risk of cancer: A meta-analysis. PeerJ. 2016;4:e1724. https://doi.org/10.7717/peerj.1724 PMid:27019773 